\title{
Non-isothermal decomposition of 4-((4-fluoro-3-phenoxy- benzylidene) amino) benzenesulfonamide under oxygen atmosphere
}

Jaganathan Venkatesan ${ }^{\mathrm{a}}$, Mahalingam Sekar ${ }^{\mathrm{a},{ }^{*}}$, Venugopal Thanikachalam ${ }^{\mathrm{b}}$, Govindasamy Manikandan ${ }^{\mathrm{b}}$

${ }^{a}$ PG \& Research Department of Chemistry, Government Arts College, C. Mutlur, Chidambaram608 102, India.

${ }^{b}$ Department of Chemistry, Annamalai University, Annamalainagar-608 002, India.

*Corresponding Author, Email: drmschemgac@gmail.com, Phone: +91 4144225610, mobile:

$+919442215610$

\section{ABSTRACT}

Sulfonamide Schiff's base namely, 4-((4-fluoro-3-phenoxybenzylidene) amino) benzene sulfonamide (4-FBABS) has been synthesized from 4-fluoro-3-phenoxybenzaldehyde, 4aminobenzenesulfonamide and few drops of glacial acetic acid by condensation method and characterized by microanalysis, Fourier transform Infrared (FT-IR) and NMR $\left({ }^{1} \mathrm{H}\right.$ and ${ }^{13} \mathrm{C}$ ) spectroscopic techniques. The thermal decomposition of 4-FBABS was studied by thermogravimetry/derivative thermogravimetry analysis (TG-DTG) under dynamic oxygen atmosphere at different heating rates of 10,15 and $20 \mathrm{~K} \mathrm{~min}^{-1}$. The decomposition process of 4-FBABS is two steps as evidenced from thermogram. The kinetic parameters were estimated using model-free methods (Friedman, Kissinger-Akahira-Sunose (KAS) and Flynn-Wall-Ozawa (FWO)) and model-fitting method (Coats-Redfern (CR)). Invariant kinetic parameters of compound are consistent with the average values obtained by Friedman and KAS isoconversional methods of compound and each step decomposed in different kinetic models. The calculated $\Delta \mathrm{G}^{\neq}$values show that the decomposition processes are endothermic and nonspontaneous nature.

Keywords: Sulfonamide Schiff's base, thermal decomposition, TG-DTG, model free methods, model fitting method, kinetic models, thermodynamic parameters. 


\section{Specifications Table}

\begin{tabular}{ll}
\hline Subject area & Thermal analysis \\
Compound & 4-((4-fluoro-3-phenoxybenzylidene) amino) benzene sulfonamide \\
Data category & Synthesis, spectral data, thermal decomposition \\
Data acquisition format & Elemental analysis, FT-IR, NMR and TG-DTG \\
Data type & Analyzed data \\
Procedure & Structure and thermal characterization \\
Data accessibility & Data are with the article
\end{tabular}

\section{Rationale}

Sulfonamide and their different derivatives are used as diuretics [1-3], antitumor [4] metalloenzymes that catalyze the hydration of carbon dioxide to bicarbonate and a proton [5-10]. Sulfonamide derivatives widely used in pharmacological agents with wide variety of biological actions, were designed from the simple sulfanilamide lead molecules [11]. Sulfonamide Schiff's bases are also used as anticancer, anti-viral agents [12] and its metal complexes have been widely studied, because they have industrial, anti-bacterial, anti-fungal, anti-tubercular [13], anticancer herbicidal applications [14] and chelating abilities which give it remarkable attention [15]. Literature survey reveals that no work has been reported on thermal decomposition of sulfonamide Schiff's base under non-isothermal decomposition in the presence of dynamic oxygen atmosphere. This prompted us to carry out the synthesis, spectral characterization and thermal studies of 4-((4-fluoro-3-phenoxybenzylidene) amino) benzene sulfonamide (4-FBABS).

\section{Procedure}

\subsection{Materials}

Starting materials obtained from commercially sources BDH chemicals of AnalaR grade 4-aminobenzene sulfonamide, Sd fine chemicals of AnalaR grade 4-fluoro-3-phenoxy benzaldehyde were used without purification. Analytical grade solvents like ethanol, ethyl acetate, hexane and dimethyl sulfoxide (DMSO) were used as such without further purification. 


\subsection{Methods}

Analytical Thin Layer Chromatography (TLC) was performed on pre-coated plastic sheets of silica gel G/UV-254 of $0.2 \mathrm{~mm}$ thickness. Melting points of the synthesized compound was determined in open-glass capillaries on a Mettler FP51apparatus and recorded in ${ }^{0} \mathrm{C}$ without correction. Elemental analyses were performed in EURO VECTOR EA 3000 at Central Leather Research Institute (CLRI), Chennai, India. FT-IR measurement was done as $\mathrm{KBr}$ pellets for solids using SHIMADZU-2010 Fourier transform Infra-Red (FT-IR) spectrophotometer (4000$400 \mathrm{~cm}^{-1}$ ). The ${ }^{1} \mathrm{H}$ and ${ }^{13} \mathrm{C}$ NMR spectra were recorded in DMSO- $d_{6}$ using TMS as internal standard with Bruker $400 \mathrm{MHz}$ and $100 \mathrm{MHz}$ high resolution NMR spectrometer.

\subsection{Thermal analysis}

The simultaneous TGA/DTG curves were obtained with the thermal analysis system model Perkin Elmer TGA 4000 V1.04 at National Institute of Technology, Trichy, India. The TG analysis of 4-FBABS was carried out under dynamic oxygen atmosphere using Perkin Elmer

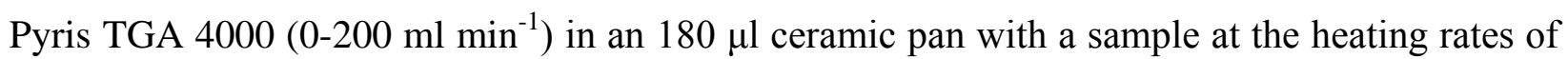
10,15 and $20 \mathrm{~K} \mathrm{~min}^{-1}$ from 35 to $700{ }^{\circ} \mathrm{C}$.

In order to ensure the uniformity of temperature of the sample and good reproducibility, small amounts (5 mg) were taken. The sample temperature controlled by thermocouple, did not exhibit any systematic deviation from the present linear temperature programme. The kinetic parameters $E_{\mathrm{a}}$ and A were calculated using Microsoft Excel Software ${ }^{\circledR}$.

\subsection{Synthesis of title compound}

The Schiff base was obtained by refluxing equimolar quantities of the 4-fluoro-3phenoxy benzaldehyde, 4-aminobenzenesulfonamide and few drops of glacial acetic acid, (0.01 mole of each in $25 \mathrm{~mL}$ ethanol) on a water bath for 5-6 hrs. The completion of the reaction, as monitored by TLC, the resulting solution was cooled at room temperature and then poured in crushed ice with constant stirring. The precipitate was filtered and washed with cold water. Then, this was recrystallized using ethanol to obtain white powdery solid (scheme 1). 


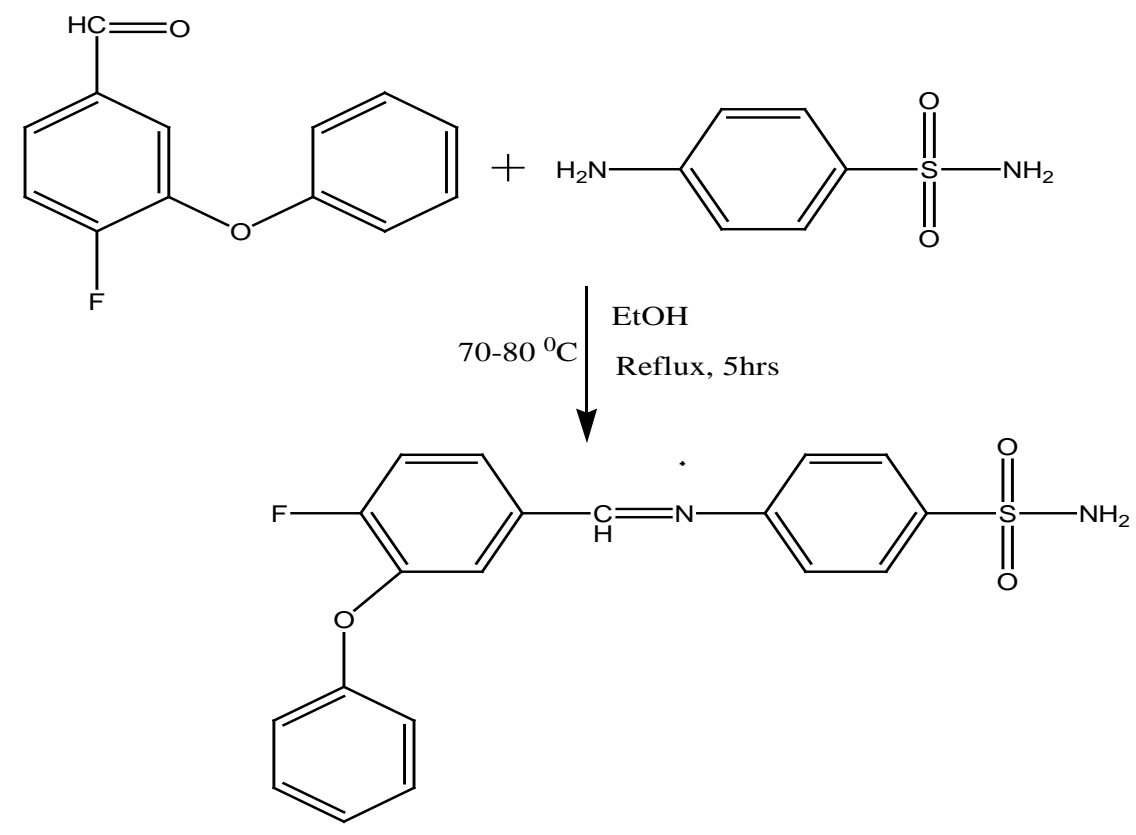

Scheme.1. Reaction pathway for the synthesis of 4-((4-fluoro-3-phenoxybenzylidene) amino) benzene sulfonamide (4-FBABS)

2.5. Theoretical calculations

Model free methods

Friedman method [16] is a differential method and is one of the first isoconversional method. The logarithmic form of equation (2) is given as

$$
\begin{aligned}
& \beta\left[\frac{\mathrm{d} \alpha}{\mathrm{dt}}\right]=A \exp \left(-\frac{\mathrm{E}}{\mathrm{RT}}\right) \mathrm{f}(\alpha) \\
& \ln \left[\beta \frac{\mathrm{d} \alpha}{\mathrm{dT}}\right]=\ln \left[\mathrm{A}_{\alpha} \mathrm{f}(\alpha)\right]-\frac{E_{a, \alpha}}{\mathrm{RT}_{\alpha}}
\end{aligned}
$$

A plot of $\ln [\beta \mathrm{d} \alpha / \mathrm{dT}]$ (or $\ln \Delta \alpha / \Delta \mathrm{t}$ ) versus $1 / \mathrm{T}$ (eqn (2)), the activation energy $E_{a}$ is obtained from the slope of the plot. The isoconversional integral methods suggested independently by Flynn and Wall [17] and Ozawa [18] uses Doyle’s [19-21] approximation of $\mathrm{p}(\mathrm{x})$. This method is based on the eq. (3),

$$
\log \beta=\log \frac{\mathrm{AE}_{\mathrm{a}}}{\operatorname{Rg}(\alpha)}-2.315-0.4567 \frac{\mathrm{E}_{\mathrm{a}}}{\mathrm{RT}}
$$

For constant conversion of $\alpha$, the left side of above equation against 1000/T, obtained from thermo grams recorded at several heating rates, should be a straight line whose slope can be 
used to evaluate the apparent activation energy for a different level of conversion and KissingerAkahira-Sunose (KAS) equation [22, 23] (Eq. (4)) is

$$
\ln \left[\frac{\beta}{T^{2}}\right]=\ln \left[\frac{A R}{E_{a} g(\alpha)}\right]-\frac{E_{a}}{R T}
$$

Thus for $\alpha=$ constant, the plot of $\ln \left(\beta / \mathrm{T}^{2}\right)$ versus $(\mathrm{l} / \mathrm{T})$ should be a straight line, apparent activation energy obtained from the slope of plot.

\section{Model fitting method}

Coats-Redfern method [24], which has been successfully used for studying the kinetics of dehydration and decomposition of different solid substances [24, 25]. The kinetic parameters can be derived from modified Coats and Redfern Eq. (5),

$$
\begin{aligned}
& \ln \left[\frac{g(\alpha)}{T^{2}}\right]=\ln \left[\frac{A R}{\beta E_{a}}\left(1-\left(\frac{2 R T_{\text {exp }}}{E_{a}}\right)\right)\right]-\frac{E_{a}}{R T} \\
& \cong \ln \left[\frac{A R}{\beta E_{a}}\right]-\left(\frac{E_{a}}{R T}\right)
\end{aligned}
$$

Where $\mathrm{g}(\alpha)$ is an integral form of the conversion function, the expression of which depends on the kinetic model of the occurring reaction. If the correct $\mathrm{g}(\alpha)$ function is used, a plot of $\ln$ $\left[\mathrm{g}(\alpha) / \mathrm{T}^{2}\right]$ against $\mathrm{l} / \mathrm{T}$ gives a straight line, from the slope and intercept of the plot to determine $\mathrm{E}_{\mathrm{a}}$ and the pre-exponential factor (A).

\section{Invariant kinetic parameters (IKP) method}

The invariant kinetic parameters method was applied to the data calculated for the different heating rates. Criado and Morales [26] observed, that almost any $\alpha=\alpha(\mathrm{T})$ or $(\mathrm{d} \alpha / \mathrm{dt})=$ $(\mathrm{d} \alpha / \mathrm{dt})(\mathrm{T})$ experimental curve may be correctly described by several conversion functions. Further, the values of the activation energy obtained for various $f(\alpha)$ for single non-isothermal curve are correlated through the compensation effect.

$$
\ln A_{i n v}=a_{\beta}+b_{\beta} E_{i n v}
$$


The above Eq. (6) represents a linear relationship between $\ln A_{\text {inv }}$ and $E_{\text {inv }}$ [27] any increase in the magnitude of one parameter is offset, or compensated, by appropriate increase of the other. Plotting $\ln \mathrm{A}_{\text {inv }}$ versus $\mathrm{E}_{\text {inv }}$ for different heating rates, the compensation effect parameters $a_{\beta}$ and $b_{\beta}$ were obtained from the intercept and slope of this plot. These parameters follow an eq. (7),

$$
a_{\beta}=\ln A_{i n v}-b_{\beta} E_{\text {inv }}
$$

The plot of $a_{\beta}$ versus $b_{\beta}$, gives true values of $E_{\text {inv }}$ and $\ln A_{\text {inv }}$ [28] are obtained from the slope and intercepts of this plot.

Determination of pre-exponential (frequency) factor and decomposition kinetic model

Based on the apparent activation energy $\left(E_{a}\right)$ and reaction (conversion) model $[g(\alpha)]$, the value of $A$ can be calculated from Eq. (8), in accordance with dependence $g(\alpha)$ versus $E_{a} p(x) / R \beta$.

$$
g(\alpha)=\frac{A E_{a}}{R \beta} p(x)
$$

Where $\mathrm{g}(\alpha)$ is the integral form of the reaction model and $\mathrm{p}(\mathrm{x})$ is the temperature integral, for $x=E_{a} / R T$, which does not have analytical solution. For calculating the value of $A$ for the investigated decomposition process, the fourth rational expression of Senum and Yang [29] for $p(x)$ function was used. From the plot of $g(\alpha)$ versus $E_{a} p(x) / R \beta$, frequency factor (A) can be determined from the slope of the plot.

Thermodynamic parameters

The kinetic parameters, energy of activation $\left(E_{a}\right)$ and pre-exponential factor (A)are obtained from Kissinger single point [22,30,31] kinetic method using the Eq. (9):

$$
\ln \left[\frac{\beta}{\mathrm{T}_{m}^{2}}\right]=\ln \left[\frac{\mathrm{AR}}{\mathrm{E}_{\mathrm{a}}}\right]-\frac{\mathrm{E}_{\mathrm{a}}}{\mathrm{RT}_{m}}
$$

Where, $\mathrm{T}_{\mathrm{m}}$ is temperature that corresponds to the maximum of $\mathrm{d} \alpha / \mathrm{dT}$. This 'model-free' kinetic method can be applied with a reasonable approximation without being limited to $n$-order kinetics [32], providing a single $E_{a}$ value for each reaction step. For this reason, it is often 
defined as a Kissinger single point method. The reaction proceeds under conditions where thermal equilibrium is always maintained, then a plot of $\ln \left(\beta / T_{m}{ }^{2}\right)$ versus $1 / T_{m}$ gives a straight line with a slope equal to $-E_{a} / R$.

Based on the values of activation energy and pre-exponential factor for the decomposition stage, thermodynamic parameters $\Delta \mathrm{S}^{\ddagger}, \Delta \mathrm{H}^{\ddagger}$ and $\Delta \mathrm{G}^{\ddagger}$ for the formation of activated complex from the reactant were calculated based on the following [32-34] equations:

$$
A=\frac{e^{e k_{B} T_{P}}}{h \exp }\left(\frac{\Delta S^{\ddagger}}{R}\right)
$$

The change of entropy may be calculated according to the formula,

$$
\begin{aligned}
& \Delta S^{\neq}=R \ln \frac{\mathrm{Ah}}{\mathrm{e} \mathrm{k}_{\mathrm{B}} \mathrm{T}_{\mathrm{P}}}\left(\frac{\Delta \mathrm{S}^{\ddagger}}{\mathrm{R}}\right) \\
& \Delta \mathrm{H}^{\neq}=\mathrm{E}_{\mathrm{a}}-\mathrm{RT}_{\mathrm{p}}
\end{aligned}
$$

Where, $\mathrm{e}=2.7183$ is the Neper number: $\chi=$ transition factor, which unity for monomolecular reaction; $\mathrm{k}_{\mathrm{B}}=$ Boltzmann constant, $1.3807 \times 10^{-23} \mathrm{JK}^{-1} ; \mathrm{h}=$ Planck constant, $6.626 \times 10^{-34} \mathrm{Js}^{-1}$ and $\mathrm{T}_{\mathrm{p}}=$ peak temperature of DTG curve.

The changes in enthalpy $\left(\Delta \mathrm{H}^{\ddagger}\right)$ and Gibbs free energy $\left(\Delta \mathrm{G}^{\ddagger}\right)$ for the activated complex formation from the reactant can be calculated using the well-known thermodynamic equation

$$
\Delta \mathrm{G}^{\neq}=\Delta \mathrm{H}^{\neq}-\mathrm{T}_{\mathrm{p}} \Delta \mathrm{S}^{\neq}
$$

\section{Data, Value and Validation}

\subsection{Spectral data}

Yield 90 \%, mp: $105{ }^{0} \mathrm{C}$;Anal. Calculated (\%) for $\mathrm{C}_{19} \mathrm{H}_{15} \mathrm{FN}_{2} \mathrm{O}_{3} \mathrm{~S}$ : C 61.61, H 4.08, N 7.56; Found (\%): C 61.59, H 4.07, N 7.58. IR (KBr, v $v_{\max }$, neat) $\mathrm{cm}^{-1}$ : $3309\left(\mathrm{NH}_{2}\right), 2989(\mathrm{CH})$, $1618(\mathrm{C}=\mathrm{N}), 1508(\mathrm{C}=\mathrm{C})\left(\mathrm{NO}_{2}\right), 1153(\mathrm{O}=\mathrm{S}=\mathrm{O}), 839$ (C-S) (Fig. S1); ${ }^{1} \mathrm{H}-\mathrm{NMR}\left(\mathrm{DMSO}-d_{6}\right) \delta$ ppm: 8.59 (s, 1H, CH), 7.06-7.91 (m, 12H, Ar-H), (Fig. S2); ${ }^{13} \mathrm{C}$ NMR (DMSO-d $\left.d_{6}\right) \delta$ ppm: 
118.49, 121.43, 122.15, 124.77, 127.84, 157.12 (aromatic carbons), 131.04 (C-S), 154.76 (C-N), $161.85(\mathrm{C}=\mathrm{N})$, (Fig. S3).

\subsection{Non-isothermal TGA}

The themogram of pure 4-FBABS recorded in a dynamic oxygen atmosphere at different heating rates of 10,15 and $20 \mathrm{~K} \mathrm{~min}^{-1}$ are presented in Fig. 1. The thermal decomposition process of 4-FBABS is observed into two steps with endothermic nature. The first stage of decomposition process for 4-FBABS, starts at 525-537 $\mathrm{K}$ and ends at 706-730 $\mathrm{K}$ with the mass loss of $\sim 33 \%$ which indicates that removal of 4 -fluorophenoxy group cal. mass loss $30 \%$ and second stage starts at 706-730 K and ends at 876-902 K with the mass loss of $\sim 67 \%$ removal of sulfonamide and Schiff's base group at different heating rates.
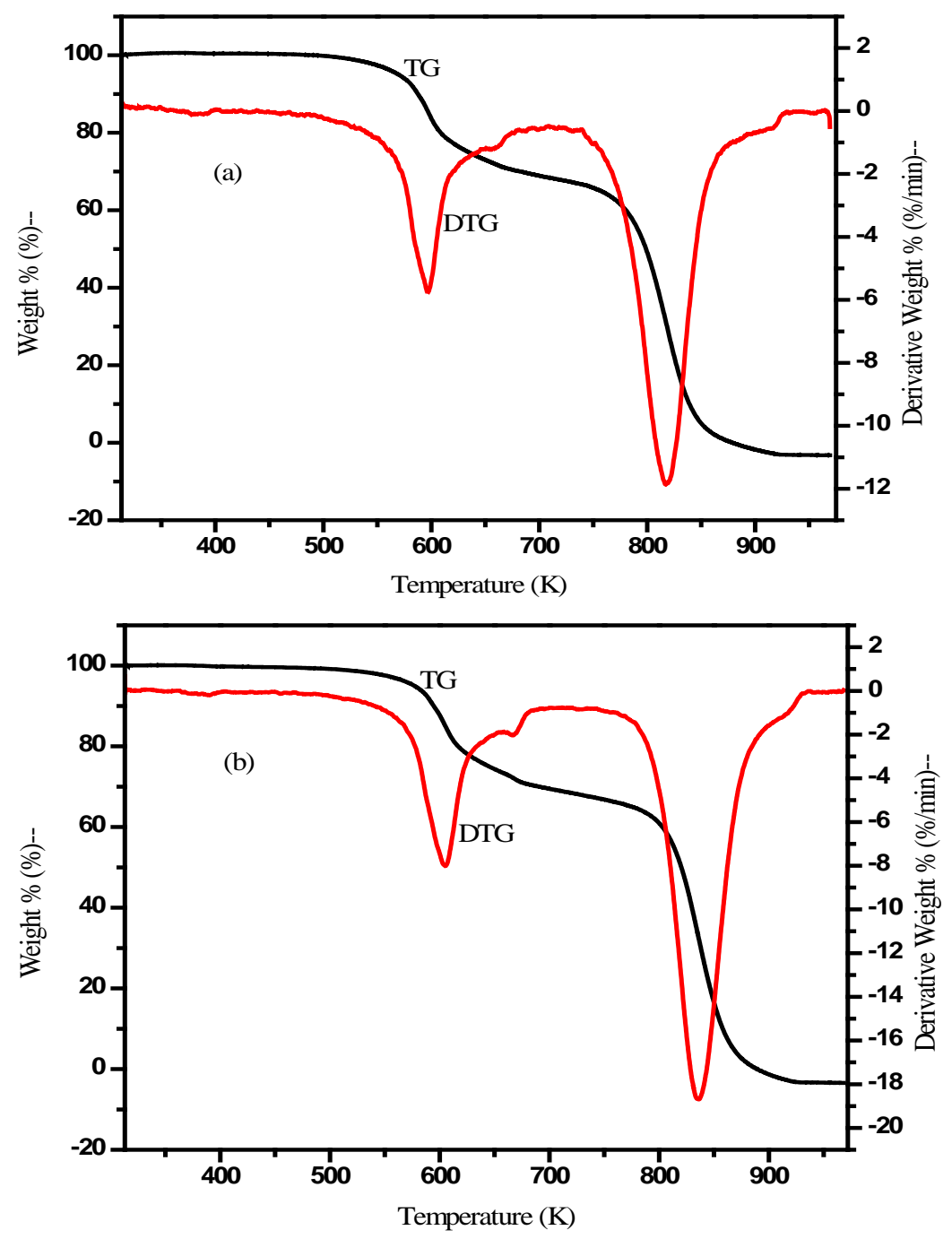


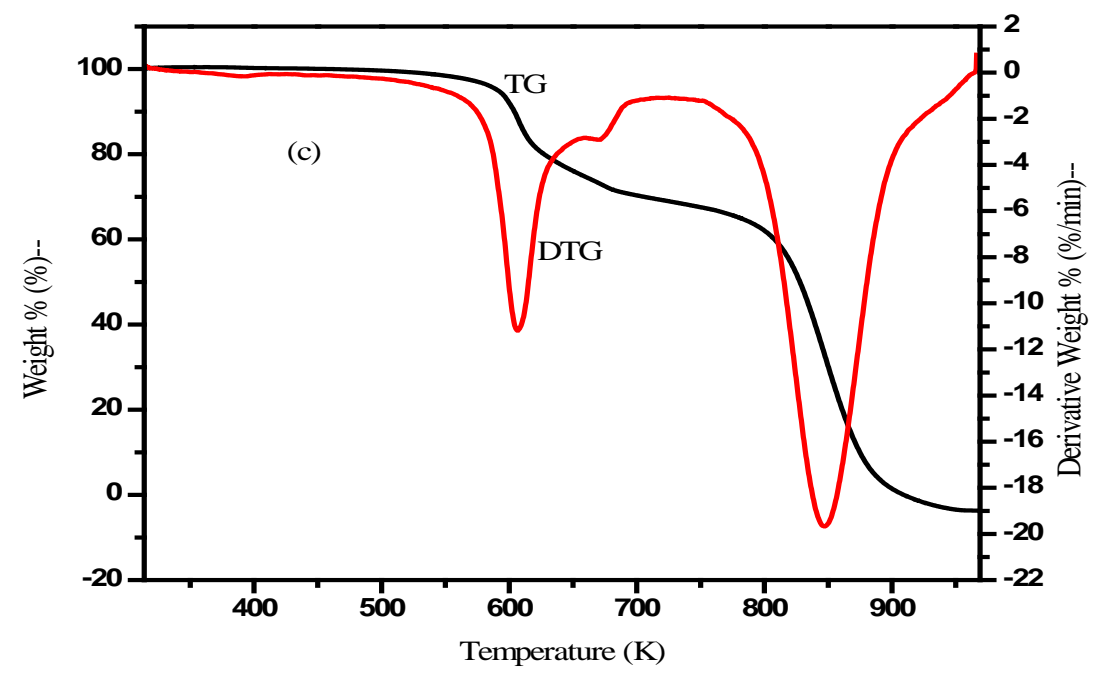

Fig. 1. TG and DTG Curves of 4-FBABS at (a) $10 \mathrm{~K} \mathrm{~min}^{-1}$ (b) $15 \mathrm{~K} \mathrm{~min}^{-1}$ and (c) $20 \mathrm{~K} \mathrm{~min}^{-1}$ heating rates in oxygen atmosphere

\subsection{Model-free analysis}

All results of non-isothermal TG analyses under an oxygen atmosphere and typical results of those under oxidizing atmospheres are shown in Fig. 1. The obtained TG analysis data for the described stages of the compound 4-FBABS were analyzed to determine the activation energy for a different level of conversion using Eq. (4).

Slopes of the regression lines in the conversional plots for the each stage, which are shown in Figs. 2 and 3, were used to calculate the activation energy at each conversion degree. The non-isothermal decomposition kinetics of 4-FBABS is first analyzed by model-free methods viz., Flynn-Wall-Ozawa, Kissinger-Akahira-Sunose and Friedman (Tables S1 and S2) show that the variation of apparent activation energy $E_{a}$, as a function of extent of conversion $\alpha$, for decomposition of 4-FBABS. $E_{a}$ values slightly variation in the conversion range of $0.05 \leq \alpha \leq$ 0.95. It was pointed out [35] that when $E_{a}$ changes with $\alpha$, the Friedman, Flynn-Wall-Ozawa and KAS isoconversional methods lead to different values of $\mathrm{E}_{\mathrm{a}}$. The applied isoconversional methods do not suggest a direct way for evaluating either the pre-exponential factor (A) or the analytical form of the reaction model $f(\alpha)$, for the investigated decomposition process of 4-FBABS. 


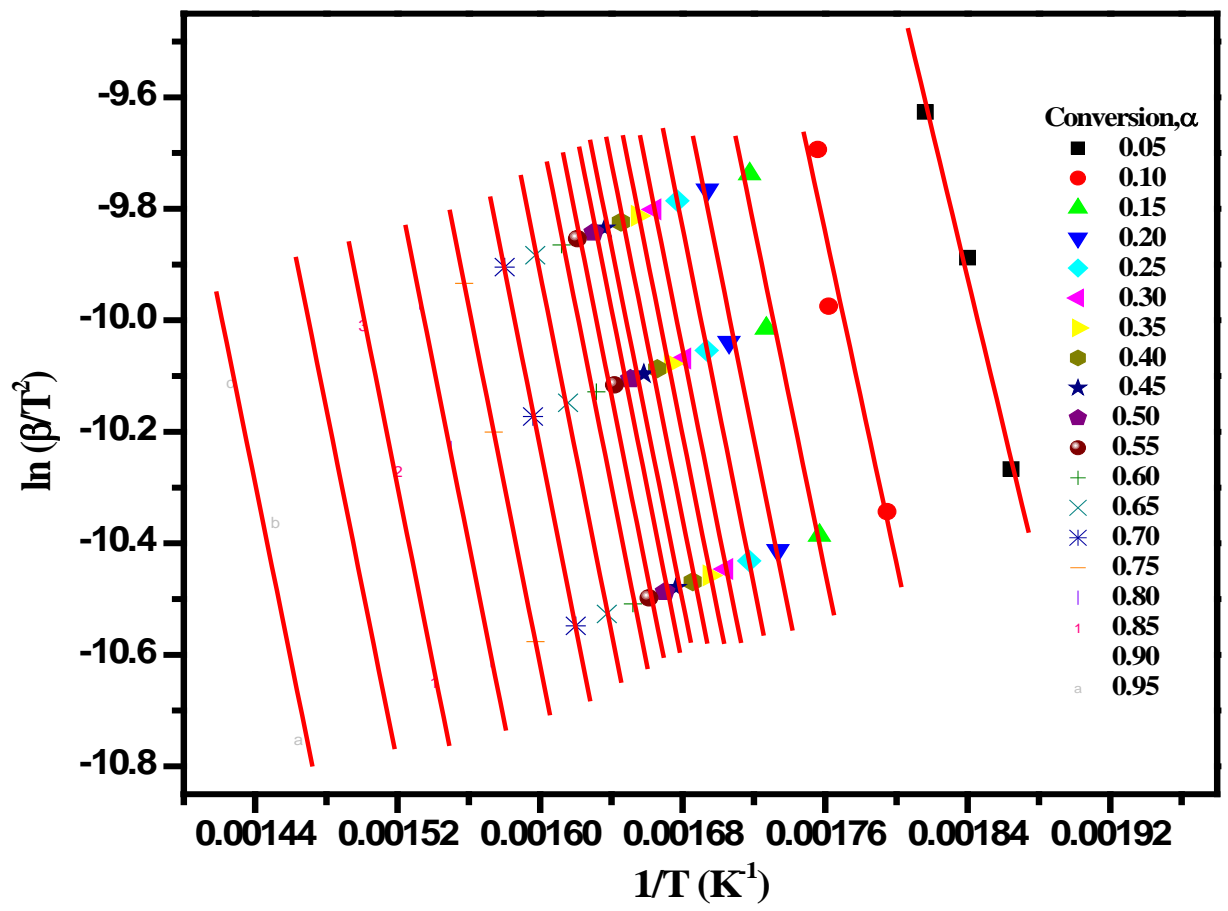

Fig.2. Slopes of the regression lines in the isoconversional plots for 4-FBABS (Stage I)

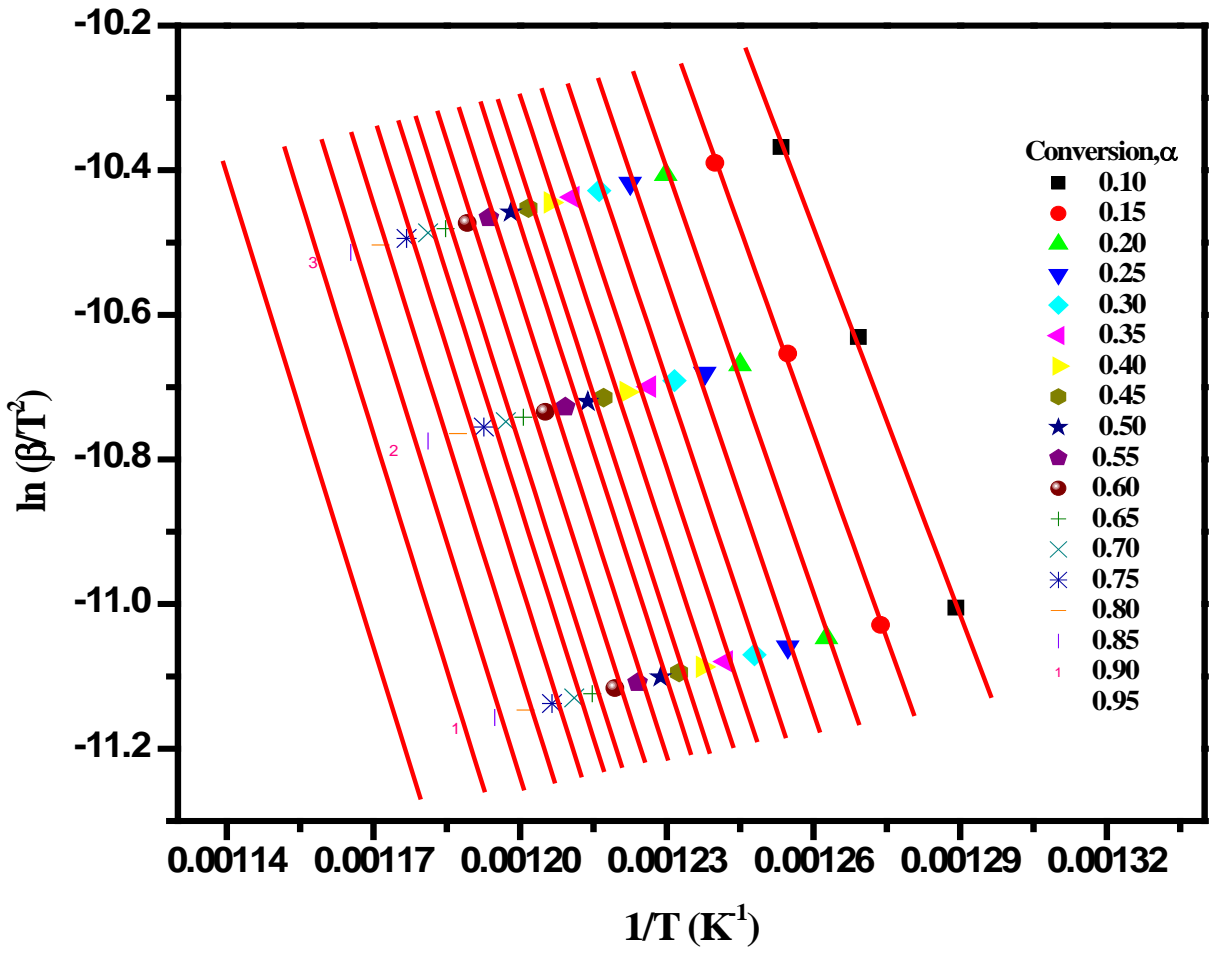

Fig.3. Slopes of the regression lines in the isoconversional plots for 4-FBABS (Stage II) 
For the two stages decomposition of 4-FBABS, the values of energy of activation corresponding to the different values of $\alpha$ for the decomposition process obtained by Friedman, KAS and FWO methods are used to determine kinetic parameter and are listed in Tables S1 (Fig.S4) and S2 (Fig. S5). $E_{\mathrm{a}}$ values slightly constant in the conversion range of $0.05 \leq \alpha \leq 0.95$ for first stage and increases slightly in the conversion range of $0.10 \leq \alpha \leq 0.95$ for second stage.As can be seen from Table S1 (Fig.S4) the variation of apparent activation energy $E_{a}$, as a function of extent of conversion $\alpha$, for decomposition of 4-FBABS.The average value of $E_{a}$ is $134.37 \pm 5.56 \mathrm{~kJ} \mathrm{~mol}^{-1}$ (FWO method), Friedman and KAS methods $\left(133.55 \pm 0.20 \mathrm{~kJ} \mathrm{~mol}^{-1}\right.$, Friedman; $131.16 \pm 5.49 \mathrm{~kJ} \mathrm{~mol}^{-1}$, KAS) are slightly lower than FWO method.

In the second stage decomposition of 4-FBABS, the variation of $\mathrm{E}_{\mathrm{a}}$ with $\alpha$ for the decomposition is shown in Table S2 (Fig. S5). The average value of $E_{a}$ is $187.92 \pm 0.31 \mathrm{~kJ} \mathrm{~mol}^{-1}$ (Friedman method). From Table S2, it is evident that the Friedman method activation energy is higher than the values obtained by KAS $\left(E_{a}=172.20 \pm 8.97 \mathrm{~kJ} \mathrm{~mol}^{-1}\right)$ and FWO $\left(E_{a}=176.77 \pm\right.$ $8.83 \mathrm{~kJ} \mathrm{~mol}^{-1}$ ) methods, from the $E_{\mathrm{a}}$ value we conclude that rate of decomposition in stage II is slower, compare to stage $\mathrm{I}$, because average value of $\mathrm{E}_{\mathrm{a}}$ is higher than first decomposition stage.

\subsection{Model-fitting analysis}

After model-free analysis is performed, model-fitting can be done in the conversion region where apparent activation energy is approximately constant where a single model may fit. The non-isothermal kinetic data of 4-FBABS at $0.05 \leq \alpha \leq 0.95$ where model-free analyses indicate that activation energy approximately constant, were then fitted into each of the 15 models are listed in (Tables S3 and S4) for both the stages, respectively. As shown in (Tables S3 and S4) for the applied method [30], Arrhenius parameters ( $\left.E_{a}, \ln A\right)$ exhibit strong dependence on the reaction model chosen.

\subsection{Invariant kinetic parameter (IKP) analysis}

Lesnikovich and Levchik [36] suggested that correlating these values by the apparent compensation effect, ln $\mathrm{A}=\mathrm{a}_{\beta}+\mathrm{b}_{\beta} \mathrm{E}_{\mathrm{a}}$, one obtains the compensation effect parameters $\mathrm{a}_{\beta} a n d \mathrm{~b}_{\beta}$, which strongly depend on the heating rates $(\beta)$ as well as on the considered set of conversion functions. The invariant kinetic parameters method was applied to the data calculated for the heating rates 10,15 and $20 \mathrm{~K} \mathrm{~min}^{-1}$. The evaluation of the kinetic parameters was performed using Coats-Redfern method. For these kinetic models in the range $0.05 \leq \alpha \leq 0.95$ for 4 -FBABS 
(stage I) and $0.10 \leq \alpha \leq 0.95$ for 4 -FBABS (stage II), the straight lines corresponding to CoatsRedfern method is characterized by correlation coefficient values close to unity and also values close to the mean isoconversional activation energies [37-39].

The apparent kinetic parameters for the thermal decomposition in oxygen atmosphere for 4-FBABS are represented in $\ln A$ versus $E_{a}$ (Figs.S6 and S7). The evaluation of the invariant kinetic parameters is performed using the super correlation Eq. (7). The plot of $a_{\beta}$ versus $b_{\beta}$, $E_{\text {inv }}$ and $\ln \mathrm{A}_{\text {inv }}$ values were obtained from the slope and intercept of straight line plot, respectively. The detailed images of the plots for 4-FBABS (stages I, II) (Figs. S6 and S7), (undersized figure in up-left corner) show the incompatibility of few models among all other conversion functions, although it's apparent parameters were obtained with high correlation coefficients.

For 4-FBABS, in stage I for AKM- $\{\mathrm{D} 1, \mathrm{D} 2, \mathrm{D} 3\}$, the plots of ln A versus $\mathrm{E}_{\mathrm{a}}$ have highest correlation coefficient, $a_{\beta}$ and $b_{\beta}$ are obtained from the slope and intercept, respectively, plot of $a_{\beta}$ versus $b_{\beta}$, we determined (Table S5; Fig. S6) invariant kinetic parameters $E_{\text {inv }}=134.13 \pm 1.63 \mathrm{~kJ}$ $\mathrm{mol}^{-1}$ and $\ln \mathrm{A}_{\text {inv }}=24.96 \pm 0.34 \mathrm{~A} \mathrm{~min}^{-1}$ (Table S7) with $\mathrm{r}=1.000$ (Fig. S8). For thesegroups, the invariant activation energy is almost equal to $134.13 \pm 1.63 \mathrm{~kJ} \mathrm{~mol}^{-1}$ in comparison with FWO, Friedman and KAS methods (134.37 $\pm 5.56 \mathrm{~kJ} \mathrm{~mol}^{-1}$, FWO; $133.55 \pm 0.20 \mathrm{~kJ} \mathrm{~mol}^{-1}$, Friedman; $131.55 \pm 5.49 \mathrm{~kJ} \mathrm{~mol}^{-1}$, KAS).

For 4-FBABS, in stage II AKM- $\mathrm{D} 1 ; \mathrm{D} 2 ; \mathrm{D} 3\}$, the plots of $\ln \mathrm{A}$ versus $\mathrm{E}_{\mathrm{a}}$ at different heating rates have the highest correlation coefficient and gave straight line (Table S6 ; Fig. S7). Plots of $a_{\beta}$ versus $b_{\beta}$, invariant kinetic parameter $E_{\text {inv }}=176.63 \pm 20.18 \mathrm{~kJ} \mathrm{~mol}^{-1}$ and $\ln \mathrm{A}_{\text {inv }}=$ $24.08 \pm 3.02 \mathrm{~A} \mathrm{~min}^{-1}$ (Table S8) with $\mathrm{r}=0.994$ (Fig. S8). For these groups, the invariant activation energy $176.63 \pm 20.18 \mathrm{~kJ} \mathrm{~mol}^{-1}$ is equal to values determine by FWO, KAS and Friedmanmethods (176.77 $\pm 8.83 \mathrm{~kJ} \mathrm{~mol}^{-1}$, FWO; $172.20 \pm 8.97 \mathrm{~kJ} \mathrm{~mol}^{-1}$, KAS; $187.92 \pm 0.31 \mathrm{~kJ}$ $\mathrm{mol}^{-1}$, Friedman). The rate of decomposition of first stage is faster when compare to second stage of 4-MBABS, due to higher energy of activation for stage II.

\subsection{Kinetic model determination}

The most suitable kinetic model for the decomposition process of 4-FBABS is F2 for stage I and F1 for stage II respectively. For stage I, by introducing the derived reaction model $g(\alpha)=(1-\alpha)^{-1}-1$, the following equation is obtained [40]. 


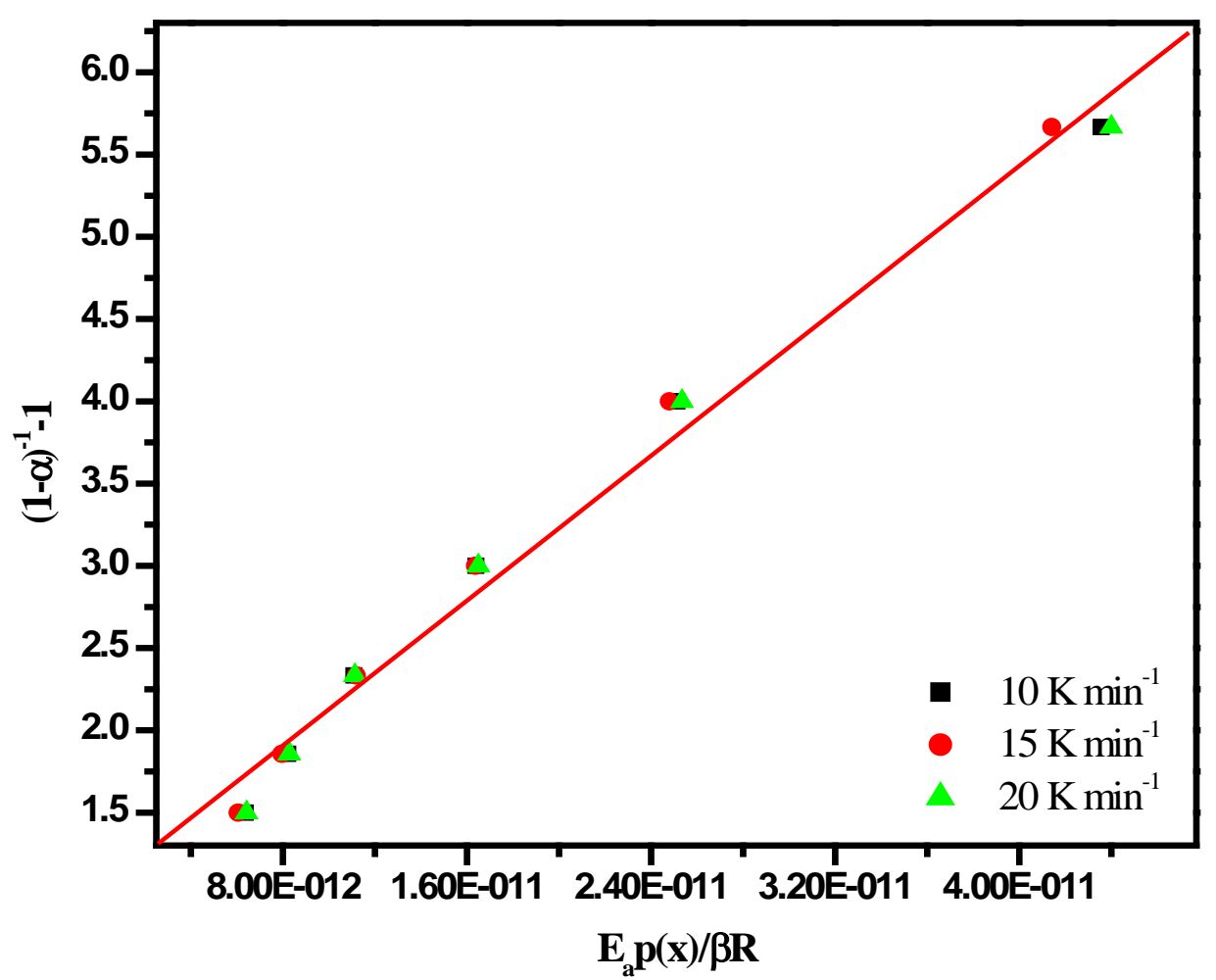

Fig. 4. Determination of $A$ value by plotting $\left[(1-\alpha)^{-1}-1\right]$ against $E_{a} p(x) / \beta R$ for the decomposition of 4 -FBABS at different heating rates $(\beta)$ (stage I)

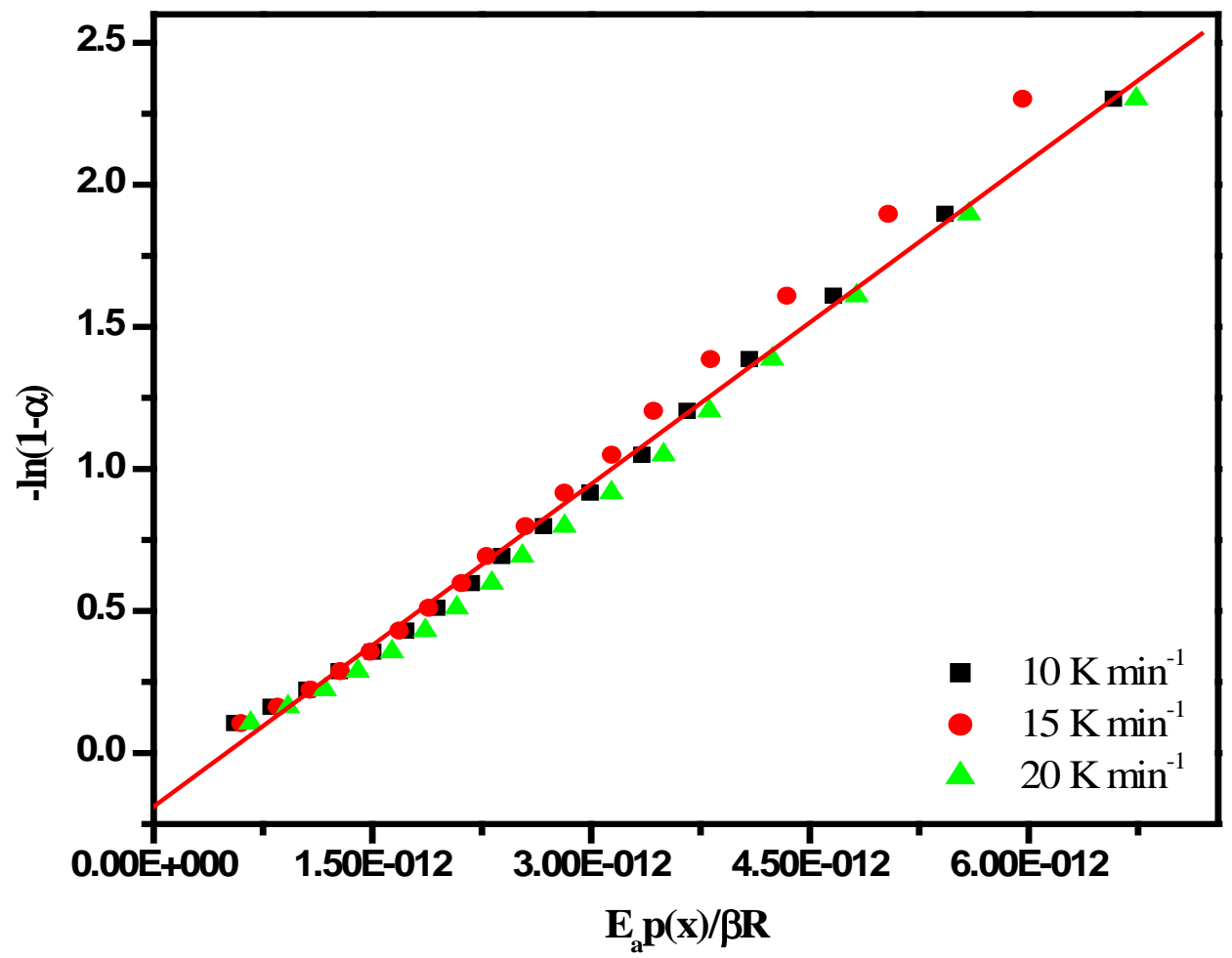

Fig. 5. Determination of A value by plotting $[-\ln (1-\alpha)]$ against $E_{a} p(x) / \beta R$ for the decomposition of 4 -FBABS at different heating rates $(\beta)$ (stage II) 


$$
(1-\alpha)^{-1}-1=\mathrm{AE} \mathrm{a}(\mathrm{x}) / \mathrm{R} \beta
$$

For stage II, by introducing the derived integral reaction model $g(\alpha)=-\ln (1-\alpha)$, the following equation is obtained.

$$
-\ln (1-\alpha)=A E_{a} p(x) / R \beta
$$

The plots of $(1-\alpha)^{-1}-1$ and $-\ln (1-\alpha)$ against $E_{a} p(x) / \beta R$ at the different heating rates are shown in Figs. 4 and 5, the most suitable model for the decomposition process is F2 and F1, respectively which indicate that decomposition mechanism depends upon nature of substituents bearing benzene nucleus. Nalini et al., have investigated the 2'-amino-6'-(1H-indol-3-yl)-2oxospiro [indole-3,4'-pyran]-3',5'-dicarbonitrile (AIOIPD) decomposition kinetic models is F2 [41] and decomposition kinetics of 1-(pyridinium-1-yl)propane-(1-methylpiperidinium)bi[bis (trifluoromethanesulfonyl) imide], [ $\left.\mathrm{PyC}_{3} \mathrm{Pi}\right]\left[\mathrm{NTf}_{2}\right]_{2}$ under $\mathrm{F} 2$ model [42]. Jingyan et al., reported a ascorbic acid compound was decomposed under F1 model [43] and carbon monofluoride under F1 model [44].

\subsection{Thermodynamic parameters}

From the DTG curves, the peak temperatures for 4-FBABS (stage I) are 596, 604 and 611 $\mathrm{K}$ and 819,831 and $841 \mathrm{~K}$ for stage IIat 10, 15 and $20 \mathrm{~K} \mathrm{~min}^{-1}$. These peak temperatures are used to evaluate single point kinetic parameters [28]. The obtained $E_{a}$ values were $130.21 \pm 7.36$ and $167.04 \pm 6.88 \mathrm{~kJ} \mathrm{~mol}^{-1}$ for stages I and II (Table 1), respectively. The thermodynamic parameters, $\Delta \mathrm{S}^{\neq}, \Delta \mathrm{H}^{\ddagger}$ and $\Delta \mathrm{G}^{\neq}$were determined at the peak temperature $\mathrm{T}_{\mathrm{m}}$ in the DTG curves for the corresponding stages[45], since the temperature characterizes the higher rate of decomposition and therefore, it is an important parameter.

As can be seen from Table 1, the value of $\Delta \mathrm{S}^{\neq}$for the decomposition is negative for both stages. It means that the corresponding activated complexes were with higher degree of arrangement than the initial stage [40]. The positive values of $\Delta \mathrm{H}^{\neq}$and $\Delta \mathrm{G}^{\neq}$show that they are connected with absorption of heat and are attributable to non-spontaneous processes $[45,46]$. The obtained $\mathrm{E}_{\mathrm{a}}$ values coincide with invariant kinetic parameter values. 


\section{Table 1}

Values of kinetic and thermodynamic parameters for the thermal decomposition 4-FBABS in oxygen atmosphere

\begin{tabular}{lll}
\hline \multirow{2}{*}{ Parameter } & \multicolumn{2}{c}{ 4-FBABS } \\
\cline { 2 - 3 } & \multicolumn{1}{c}{ Stage I } & \multicolumn{1}{c}{ Stage II } \\
\hline $\mathrm{E}_{\mathrm{a}} / \mathrm{kJ} \mathrm{mol}^{-1}$ & $130.21 \pm 7.36$ & $167.04 \pm 6.88$ \\
$\ln \mathrm{A} / \mathrm{Amin}^{-1}$ & $25.42 \pm 3.82$ & $23.30 \pm 7.71$ \\
$\Delta \mathrm{G}^{\neq} / \mathrm{k} \mathrm{Jmol}^{-1}$ & 154.00 & 216.68 \\
$\Delta \mathrm{H}^{\ddagger} / \mathrm{kJ} \mathrm{mol}^{-1}$ & 125.18 & 160.13 \\
$\Delta \mathrm{S}^{\neq} / \mathrm{J} \mathrm{mol}^{-1}$ & -47.71 & -68.05 \\
$\mathrm{r}$ & -0.998 & -0.999 \\
\hline
\end{tabular}

\section{CONCLUSION}

The compound chosen for the study decomposed into two stages. Activation energies of two stages of obtained compound could be determined from a model-free analysis of TG analysis data. Since the activation energy values varied with the conversion level, the averaged activation energy values were used to interpret decomposition models for each stages followed different kinetic models namely F2 for first stage and F1 for second stage, respectively. The positive free energy values indicate that the decomposition of studied compound is non-spontaneous process.

\section{ACKNOWLEDGMENT}

The authors thank Head of the department, CEESAT, Department of Energy and Environment (DEE), National Institute of Technology, Triuchirapalli-620 015, Tamil nadu, India, for recorded TGA and DTG analyses.

\section{SUPPORTING INFROMATION}

Tables and figures are included in the supporting information. 


\section{References}

[1] S.M. Hassan, A.A. El-Maghraby, M.M. Abdel Aal, M.S. Bashandy, Hetero aromatization with sulfonamido phenyl ethanone, part I: synthesis of novel pyrrolo[2,3-d]pyrimidine and pyrrolo[3,2-e][1,2,4]Triazolo[1,5-c] pyrimidine derivatives containing dimethyl sulfonamide moiety,Phosphorus, Sulfur, Silicon and Relat Elem. 184 (2009) 291-308.

[2] K.M. Hilmy, M.M. Khalifa, M.A. Hawata, R.M. Keshk, A.A. el-Torgman, Synthesis of new pyrrolo[2,3- $d]$ pyrimidine derivatives as antibacterial and antifungal agents,Eur. J. Med. Chem. 45 (2010) 5243-5250.

[3] C. Temperini, A. Cecchi, A. Scozzafava, C.T. Supuran, Carbonic anhydrase inhibitorssulfonamide diuretics revisited-old leads for new applications?, Biomol. Chem. Org. 6 (2008) 2499-2506.

[4] N.S. El-Sayed, E.R. El-Bendary, S.M. El-Ashry, M.M. El-Kerdawy, Synthesis and antitumor activity of new sulfonamide derivatives of thiadiazolo[3,2-a] pyrimidines, Eur. J. Med. Chem. 46 (2011) 3714-3720.

[5] C.T. Supuran, A. Scozzafava, Carbonic anhydrase inhibitors and their therapeutic potential, Expert Opin. Ther. Pat. 10 (2000) 575-600.

[6] C.T. Supuran, Carbonic anhydrase inhibitors,Bioorg. Med. Chem. Lett. 20 (2010) 34673474.

[7] C.T. Supuran, Carbonic anhydrases: novel therapeutic applications for inhibitors and activators,Nat. Rev. Drug. Discov. 7 (2008) 168-181.

[8] T.H. Maren, Carbonic anhydrase: chemistry, physiology and inhibition,Physiol. Rev. 47 (1967) 595-781.

[9] A.J. Esbaugh, B.L. Tufts, The structure and function of carbonic anhydrase isozymes in the respiratory system of vertebrates!,Respir. Physiolo. Neurobiol. 154 (2006) 185-198.

[10] I. Nishimori, T. Minakuchi, S. Onishi, D. Vullo, A. Cecchi, A. Scozzafava, C.T. Supuran, Carbonic anhydrase inhibitors: cloning, characterization, and inhibition studies of the cytosolic isozyme III with sulfonamides,Bioorg. Med. Chem.15 (2007) 7229-7236.

[11] M. Alhassan, Z. Chohan, A. C. Scozzafava Supuran, Carbonic anhydrase inhibitors: schiff's bases of aromatic and heterocyclic sulfonamides and their metal complexes, J. Enzyme Inhib. Med. Chem. 19 (2004) 263-267. 
[12] L. Cheng, J. Tang, H. Luo, X. Jin, F. Dai, J. Yang, Y. Qian, X. Li, B. Zhou, Antioxidant and antiproliferative activities of hydroxyl-substituted Schiff bases, Bioorg. Med. Chem. Lett. 20 (2010) 2417-2420.

[13] M.L. Ferreira, T.A. Vasconcelos, E. Carvalho, M. Lourenço, S.V. Wardell, J. Wardell, V. Ferreira, M. Souza, Synthesis and antitubercular activity of novel Schiff bases derived from D-mannitol, Carbohydr. Res. 344 (2009) 2042-2047.

[14] P.G. Cozzi, Metal-salenschiff base complexes in catalysis: practical aspects, Chem. Soc. Rev. 33 (2004) 410-421.

[15] N. Raman, L. Mitu, A. Sakthivel, M.S.S. Pandi, Studies on DNA cleavage and antimicrobial screening of transition metal complexes of 4-aminoantipyrine derivatives of $\mathrm{N}_{2} \mathrm{O}_{2}$ type,J. Iran. Chem. Soc.6 (2009) 738-748.

[16] H.L. Friedman, Kinetics of thermal degradation of char-foaming plastics from thermogravimetry: Application to a phenolic plastic, J. Polym. Sci. Pol. Sym. 6(1964) 183-195.

[17] J.H. Flynn, L.A. Wall, General treatment of the thermogravimetric of polymers, J. Res. Natl. Bur. Stand. A70 (1966) 487-523.

[18] T. Ozawa, A new method of analyzing thermogravimetric data, Bull. Chem. Soc. Jpn. 38 (1965) 1881-1886.

[19] C.D. Doyle, Kinetic analysis of thermogravimetric data, J. Appl. Polym. Sci. 5 (1961) 285-292.

[20] C.D. Doyle, Series approximations to the equation of thermogravimetric data. Nature. 207 (1965) 290-291.

[21] C.D. Doyle, Estimating isothermal life from thermogravimetric data, J. Appl. Polym. Sci. 6 (1962) 639-642.

[22] H.E. Kissinger, Reaction kinetics in differential thermal analysis, Anal. Chem. 29(1957) 1702-1706.

[23] T. Akahira, T. Sunose, Joint convention of four electrical institutes, Res. Report (Chiba Inst. Technol.) 16 (1971) 22-31.

[24] A.W. Coats, J.P. Redfern, Kinetic parameters from thermogravimetric data. Nature, (London),201(1968) 68-69. 
[25] H.H. Horowitz, G.A. Metzger, New analysis of thermogravimetric traces, Anal. Chem.35(1963) 1464-1468.

[26] J.M. Criado, J. Morales, Defects of thermogravimetric analysis for discerning between first-order reactions and those taking place through the Avrami-Erofeev's mechanism, Thermochim. Acta. 16(1976) 382-387.

[27] A.I. Lesnikovich, S.V. Levchik, Isoparametric kinetic relations of chemical transformation in condensed substances,J. Therm. Anal. 30 (1985) 237-262.

[28] J.H. Flynn, The 'temperature integral'- its use and abuse, Thermochim. Acta. 300 (1997) 83-92.

[29] G.I. Senum, R.T. Yang, Rational approximations of the integral of the Arrhenius function, J. Therm. Anal. 11 (1977) 445-447.

[30] H.E. Kissinger, Variation of peak temperature with heating rate in differential thermal analysis,J. Res. Natl. Bur. Stand. 57 (1956) 217-221.

[31] D.J. Whelan, R.J. Spear, R.W. Read, The thermal decomposition of some primary explosives as studied by differential scanning calorimetry, Thermochim. Acta.80 (1984) 149-163.

[32] J. Malek, A computer program for kinetic analysis of non-isothermal thermoanalytical data, Thermochim. Acta. 136 (1989) 337-346.

[33] H.F. Cordes, Preexponential factors for solid-state thermal decomposition,J. Phys. Chem. 72(1968) 2185-2189.

[34] C.H. Bamford, C.F.H. Tipper, (Eds.) Comprehensive chemical kinetics. Reactions in the Solid State, vol.22, Elsevier, Amsterdam,1980.

[35] S. Vyazovkin, W. Linert, False isokinetic relationships found in the non-isothermal decomposition of solids,Chem. Phys. 193 (1995) 109-118.

[36] A.I. Lesnikovich, S.V. Levchik, Variation of peak temperature with heating rate in differential thermal analysis. J. Therm. Anal. 27 (1983) 89-94.

[37] S.V. Vyazovkin, A.I. Lesnikovich, Estimation of the pre-exponential factor in the isoconversional calculation of effective kinetic parameters. Thermochim. Acta, 128 (1998) 297-300. 
[38] P. Budrugeac, E. Segal, Applicability of the Kissinger equation in thermal analysis. J. Therm. Anal. Calorim. 88 (2007) 703-707.

[39] A. Pratap, T.L.S. Rao, H.D. Lad and Dhaurandhar, Isoconversional vs. model fitting methods, J. Therm. Anal. Calorim. 89 (2007) 399-405.

[40] J. Malek, The kinetic analysis of non-isothermal data. Thermochim. Acta. 200, (1992) 257-269.

[41] G. Nalini, N. Jayachandramani, V. Thanikachalam, J. Jayabharathi, G. Manikandan, R. Suresh, Kinetics of thermal decomposition of a spirooxindole compound under nonisothermal condition, Can. Chem. Trans. 4(2016) 62-76.

[42] J. Wang, M. Wang, X. Yang, W. Zou, Xiang Chen, Crystal structure and thermal decomposition kinetics of 1-(pyridinium-1-yl)propane-(1-methylpiperidinium)bi[bis (trifluoromethanesulfonyl)imide], [PyC $\left.{ }_{3} \mathrm{Pi}\right]\left[\mathrm{NTf}_{2}\right]_{2}$,Chin.J.Chem. Eng. 23 (2015) 816821.

[43] S. Jingyan, L. Yuwen, W. Zhiyong, W. Cunxin, Investigation of thermal decomposition of ascorbic acid by TG-FTIR and thermal kinetics analysis, J. Pharm. Biomed. Anal. 77 (2013) 116-119.

[44] G. Chen, Z. Shi, J. Yu, Z. Wang, J. Xub, B. Gao, X. Hu, Kinetic analysis of the nonisothermal decomposition of carbon monofluoride, Thermochim. Acta. 589 (2014) 63-69.

[45] J.M. Criado, L.A. Perez-Maqueda, P.E. Sanchez-Jimenez, The dependence of the preexponential factor on temperature, J. Therm. Anal. Calorim. 82(2005) 671-675.

[46] D.V. Sokolskii, V.A. Druz, Introduction in theory of heterogeneous catalysis, Vyshaya Shkola, Moscow, Russia, 1981. 


\section{LIST OF FIGURES:}

[1] Fig. S1 FT-IR spectrum of 4-FBABS in $\mathrm{KBr}$ disc $\left(\mathrm{cm}^{-1}\right)$

[2] Fig. $\mathbf{S 2}{ }^{1} \mathrm{H}$ NMR spectrum of 4-FBABS in DMSO $d_{6}$

[3] Fig. S3 ${ }^{13}$ C NMR spectrum of 4-FBABS in DMSO $d_{6}$

[4] Fig. S4E $E_{a}$ versus $\alpha$ plot for the decomposition of 4-FBABS (Stage I) under non-isothermal condition in oxygen atmosphere

[5] Fig. S5E $E_{a}$ versus $\alpha$ plot for the decomposition of 4-FBABS (Stage II) under non-isothermal condition in oxygen atmosphere

[6] Fig. S6ln A versus $E_{a}$ plot for AKM- $\{D 1 ; D 2 ; D 3\}$ combination at $\beta=10,15,20 \mathrm{~K} \mathrm{~min}^{-1}$ for 4-FBABS (Stage I)

[7] Fig. S7ln A versus $E_{a}$ plot for AKM- $\{D 1 ; D 2 ; D 3\}$ combination at $\beta=10,15,20 \mathrm{~K}^{-1}$ for $^{-1}$ 4-FBABS (Stage II)

[8] Fig. S8 Super correlation (compensation effect parameters) plot for the best combination models $\left(\beta=10,15,20 \mathrm{~K} \mathrm{~min}^{-1}\right)$ 